\title{
Adaptive Piecewise Linear Controller for Servo Mechanical Control Systems
}

\author{
Tain-Sou Tsay \\ Department of Aeronautical Engineering, National Formosa University, Yunlin, Taiwan \\ Email: tstsay@nfu.edu.tw
}

Received September 18, 2013; revised October 18, 2013; accepted October 27, 2013

Copyright (C) 2013 Tain-Sou Tsay. This is an open access article distributed under the Creative Commons Attribution License, which permits unrestricted use, distribution, and reproduction in any medium, provided the original work is properly cited.

\begin{abstract}
In this paper, an adaptive piecewise linear control scheme is proposed for improving the performance and response time of servo mechanical control systems. It is a gain stabilized control technique. No large phase lead compensations or pole zero cancellations are needed for performance improvement. Large gain is used for large tracking error to get fast response. Small gain is used between large and small tracking error for good performance. Large gain is used again for small tracking error to cope with disturbance. It gives an almost command independent response. It can speed up the rise time while keeping robustness unchanged. The proposed control scheme is applied to a servo system with large time lag and a complicated electro-hydraulic velocity/position servo system. Time responses show that the proposed method gives significant improvements for response time and performance.
\end{abstract}

Keywords: Piecewise Linear Controller; Nonlinear Controller; Adaptive Gain; Servo System

\section{Introduction}

This template Gain and phase stabilized are two conventional design methods for feedback control systems. They can be analyzed and designed in gain-phase plots to get wanted gain margin (GM) and phase margin (PM) or gain crossover frequency $\left(\omega_{c g}\right)$ and phase crossover frequency $\left(\omega_{c p}\right)[1,2]$. The gain crossover frequency is closely related to the system bandwidth (or rise time). The phase margin is closely related to performance (or peak overshoot). In general, fast response time and good performance can not be obtained simultaneously for some feedback control systems. For example, the altitude control system of the airframe with altitude and altitude rate feedbacks needs large altitude loop gain for fast response time and low altitude loop gain for good robustness. It is in conflict with another. A simple and effective way to solve this problem and better results for those of linear controllers is generally expected. This is the motivation of this paper. Variable structure control is a switching control method for feedback control systems [3-7]. It gives good performance and robustness for coping with system uncertainty. But it suffered from chattering problem and state measurements. In this paper, a fast response system and a good performance system are selected for switching. An adaptive switching algorithm is used. There is no discontinuous connection between two systems. Therefore, there is no chattering problem. Gain scheduling has been used successfully to control nonlinear systems for many decades and in many different applications, such as autopilots and chemical processes [8-10]. It consisted of many linear controllers for operating points to cope with large parameter variations. This concept will be expanded for response time and performance. Operating points are replaced by fast response and good performance conditions and interpolation for gain evaluation is replaced by an adaptive switching point. It is determined by the filtered command tracking errors. Nonlinear controllers syntheses using inverse describing function for use with hard nonlinear system have been developed for several researchers [11-14]. They are complicated but effective for nonlinear systems. In this paper, a simple three segments piecewise linear controller is proposed. It is easy to analyse and design. Furthermore, it gives an almost reference input independent response.

The proposed control scheme is applied to a servo system with large transportation lag and a complicated electro-hydraulic velocity/position servo system. Time responses show that the proposed method gives signifi- 
cant improvements for response time and performance.

\section{The Adaptive Piecewise Linear Controller}

\subsection{Piecewise Linear Nonlinearity}

Figure 1(a) shows piecewise linear description of the symmetrical nonlinearity. Piecewise linear segments $y_{i(+)} / y_{i(-)}$ are in the form of

$$
\begin{aligned}
& y_{1(+)}=K_{1} x \\
& y_{i(+)}=K_{i} x+\sum_{j=2}^{i}\left(K_{j-1}-K_{j}\right) D_{j-1} ; i>1 \\
& y_{1(-)}=K_{1} x \\
& y_{i(-)}=K_{i} x+\sum_{j=2}^{i}\left(K_{j-1}-K_{j}\right) D_{j-1} ; i>1
\end{aligned}
$$

Now, the problem is to determine the values of switch points $D_{i}$ and gains $K_{i}$ between $D_{i}$ and $D_{i+1}$ for the wanted responses time and performance. For illustrating purpose, two switching points $+D_{1},-D_{1}$ and two gains $K_{1}, K_{2}$ will be used to illustrate the advantage of the proposed piecewise linear controller; i.e., three segments are discussed. In this work, switching points $+D_{1}$ and $-D_{1}$ are not fixed and will be determined by the absolute value of the command tracking error of feedback control systems. The control configuration of the industry process using the piecewise linear nonlinearity and PID controller is shown in Figure 1(b). The finding of $D_{1}$ will be discussed in the next subsection.

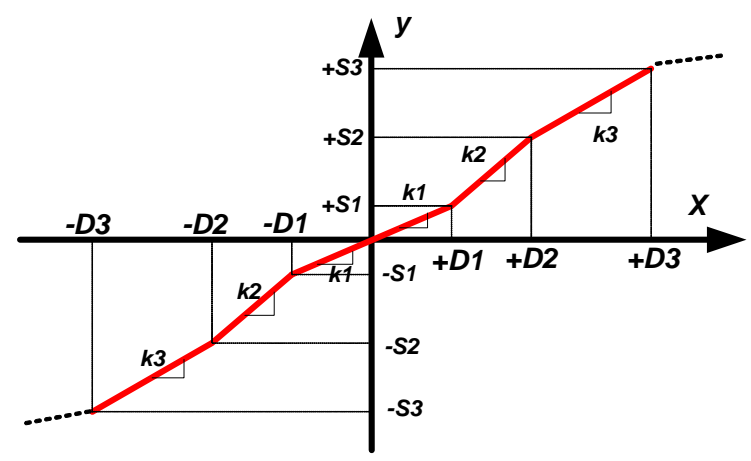

(a)

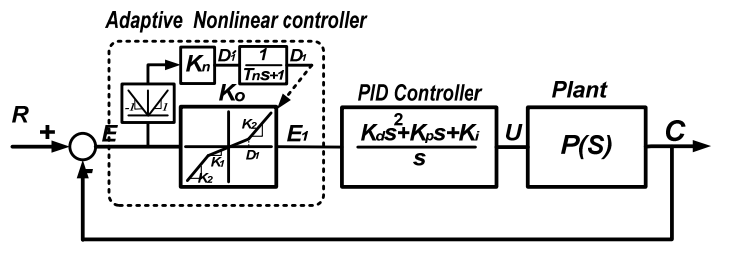

(b)

Figure 1. (a) Piecewise linear description of an adaptive gain; (b) Control configuration of the industry process using PID controller.

\subsection{Gain Adapting Using the Piecewise Linear Nonlinearity}

The loop gain of the closed-loop system can be adapted by the piecewise linear linearity. Considers a second order numerical example described by

$$
G(s)=\frac{1}{s(s+2)}
$$

It is closed with a loop gain $K$. Then the closed-loop transfer function is

$$
T(s)=\frac{K}{s^{2}+2 s+K}
$$

Poles locations and natural frequency $\left(\omega_{n}\right)$ for two loop gains $\left(K_{1}, K_{2}\right)$ are given below:

$$
\begin{aligned}
& K_{1}=0.500 \text {; poles : }-0.2929,-1.7071 ; \\
& K_{2}=10.00 \text {; poles : }-1.0 \pm j 3.0 ; \omega_{n}=3.1623 ;
\end{aligned}
$$

They are an over-damped and an under-damped systems. Time responses are shown in Figure 2 for $K=K_{1}$ (small-dot-line) and $K=K_{2}$ (large-dot-line) in which $R$ represents the reference input and $C$ represents the plant output.

The strategy for gain switching is (1) large gain $\left(K_{2}\right)$ for large tracking error to get fast response and (2) small gain $\left(K_{1}\right)$ for small tracking error $(E)$ to get good performance. It is a variable structure system and can be achieved by selecting a proper switching point $D_{1}$ of the piecewise linear controller shown in Figure 1(a). For example, the optimal switching point $D_{1}$ is selected as 0.525 for $R=1$ to get both fast response and good performance. Large gain $\left(K_{2}\right)$ is used for $|E|>D_{1}$ and small gain $\left(K_{1}\right)$ is used for $|E| \leq D_{1}$. Step response is shown in Figure 2 (solid-line) also for $R=1$. It shows that adaptive gain can give a good result for fast response and good performance.

However, it is not true for $\mathrm{R}$ is equal to 5, 10 and 50, respectively. Those step responses are shown in Figure 3. Naturally, another switching point $D_{1}$ for $R=5,10$ and

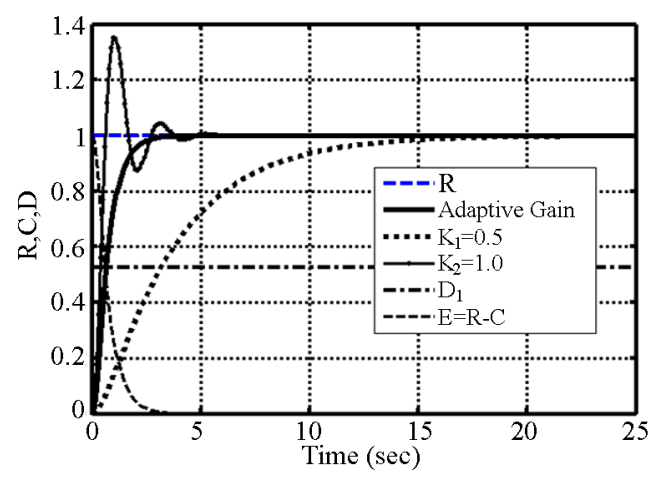

Figure 2. Time responses for $K_{1}=0.5, K_{2}=10$ and adaptive gain of the illustrating example. 
50 can be selected for getting good performance. They are $2.625,5.250$ and 26.250 for $R=5,10$ and 50, respectively. They are true for step responses from zeros to 5 , 10 and 50 only. Another possible way for the switching point can be dependent on the tracking error $(E)$. A possible switching rule for $D_{1}$ is found as $D_{1}=0.925|E|$ for good performance. Figure 3 shows time responses for $R=1,5,10$ and 50, respectively. It can be seen that the switching rule gives an input command $(R)$ independent results. However, they are slower than results shown in Figures 2 and 4.

One possible way to speed up the time response is enlarging the large gain phase in the beginning. A low-pass filter $D(s)=K_{n} /\left(T_{n} s+1\right)$ for the absolute tracking error $(E)$ to get $D_{1}$ is used. Figure 5 shows faster response is get for $K_{n}=1.0445$ and $T_{n}=1 / \omega_{n}$. The switching point $D_{1}$ is shaped for speed up the responses while keeping performance unchanged. Figure 6 shows input independent responses for $R=1,5,10$ and 50. Note that the natural frequency $\left(\omega_{n}\right)$ for $K=K_{2}$ is used to find $T_{n}$. Therefore, it is needed to find $K_{n}$ only.

The design procedures for the proposed method using the adaptive piecewise linear controller can be deduced as:

Step 1: Selecting two loop gains for fast response and good performance, respectively.

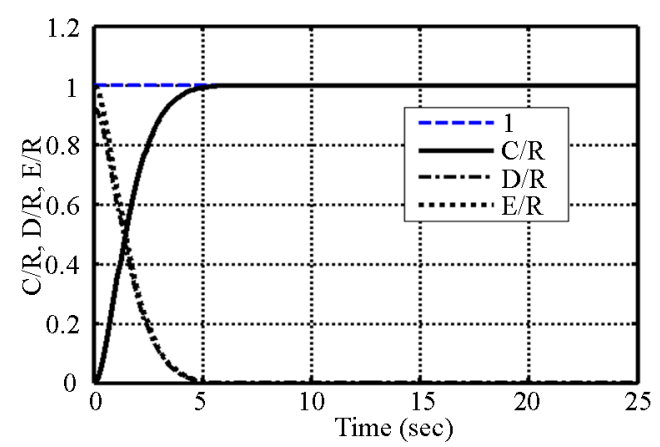

Figure 3. Time responses for $R=1,5,10,50$ using $D_{1}=0.925|E|$ of the illustrating example.

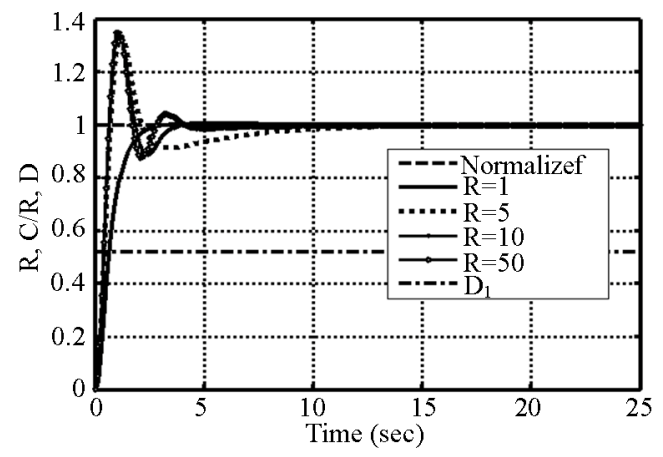

Figure 4. Time responses for $R=1,5,10,50$ using $D_{1}=$ 0.525 of the illustrating example.
In general, high loop gain $\left(K=K_{2}\right)$ for fast responses and low gain $\left(K=K_{1}\right)$ for good performance. The rise time $\left(T_{c}\right)$ of the system using high gain meets the design specification. The peak overshoot of the system with low gain meet the design specification.

Step 2: determining parameters of low-pass filter $D(s)=K_{n} /\left(T_{n} s+1\right)$ to find the optimal switching point $D_{1}$. The natural frequency $\left(\omega_{n}\right)$ for the high gain system $\left(K=K_{2}\right)$ is used to find $T_{n}$. The natural frequency $\left(\omega_{n}\right)$ is close related to the rise time. Another parameter $T_{n}$ can be found by the optimization method using performance index formulated by integration of the absolute error (IAE) and integration of the square error (ISE) or on-line parameterized method $[15,16]$. The iteration rule for finding $K_{n}$ is formulated as

$$
\begin{gathered}
G_{n}(k T+T)=G_{n}(k T) \times\left\{\alpha[M p c / M p s]^{j}+(1-\alpha)\right\} ; \\
K_{n}=G_{n}(k T+T)
\end{gathered}
$$

where Mps is the specification of the Peak point; $M p c$ is the peak point found using $K_{n}=G_{n}(k T) ; T$ is simulation period of one step response; and $k$ is the $k^{\text {th }}$ step responses.

The proposed control scheme will be applied to a servo system with large transportation lag and a compli-

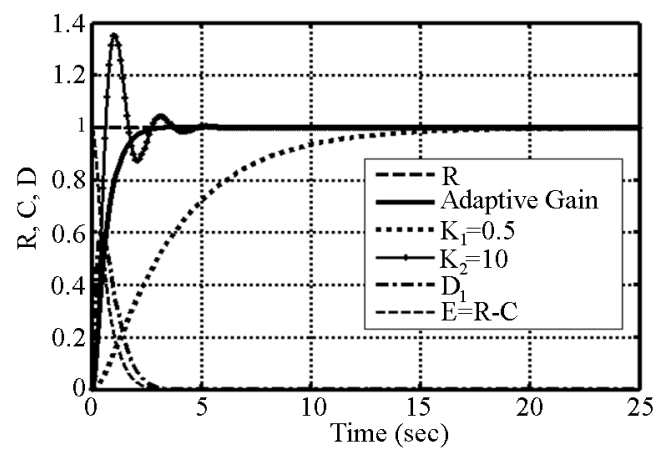

Figure 5. Time responses for $R=1$ using $D(s)=$ $K_{n} /\left(T_{n} s+1\right)$ of the illustrating example.

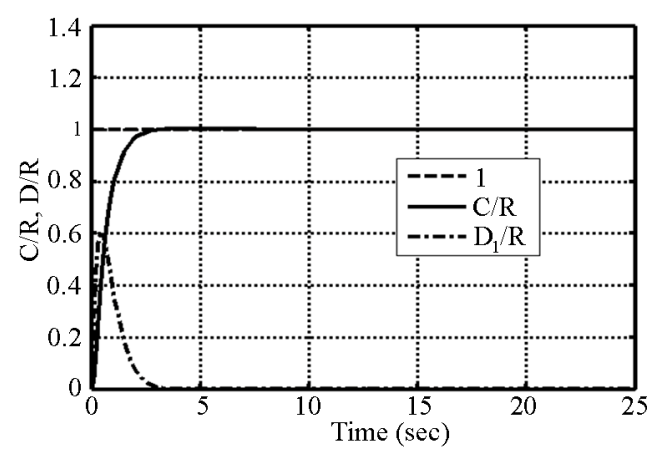

Figure 6. Time responses for $R=1,5,10$ and 50 of the illustrating example. 
cated electro-hydraulic velocity/position servo system.

\section{Numerical Example}

Example 1: Consider a stable plant has the transfer function $[16,17]$

$$
G(s)=\frac{\mathrm{e}^{-s}}{(s+1)^{2}}
$$

It is a second order dynamic plus a pure time delay (SOPDT). In this example, a PID controller with parameters

$$
K_{p}=1.1953 ; K_{i}=0.5942 ; K_{d}=0.7338 ;
$$

is designed first. And then low gain $K_{1}=0.50$ is selected and high gain $K_{2}=2.587$ is selected for the system is just in the sustaining oscillating condition. The oscillation frequency is $\omega_{n}=1.5708 \mathrm{rad} / \mathrm{s}$. Time responses using low gain $\left(K_{1}=0.5\right)$ and high gain $\left(K_{2}=2.587\right)$ are shown in Figure 7. They show an over-damped system and a zero-damped system. Now, applying the proposed control scheme to the system using $K_{1}=0.5000 ; K_{2}=2.587 ; K_{n}=1.1385 ; T_{n}=0.6366$;

The $K_{n}$ is found by following on-line computing rule:

$$
\begin{gathered}
G_{n}(k T+T)=G_{n}(k T) \times\left\{0.9[M p c / M p s]^{2}+0.1\right\} ; \\
K_{n}=G_{n}(k T+T)
\end{gathered}
$$

with $G_{n}(0)=0.5, T=25$ seconds and Mps $=1.001$. The found $G_{n}(k T)$ are

$$
\begin{aligned}
& G_{n}(0)=0.5 ; G_{n}(T)=1.0794 ; G_{n}(2 T)=1.1365 ; \\
& G_{n}(3 T)=1.1385 ; G_{n}(4 T)=1.1385 ; \cdots
\end{aligned}
$$

$G_{n}(k T)$ is converged to be 1.1385 within three period simulations. The time response is shown in Figure 7 also. It can be seen that the proposed method can give fast response and good performance simultaneously. It is

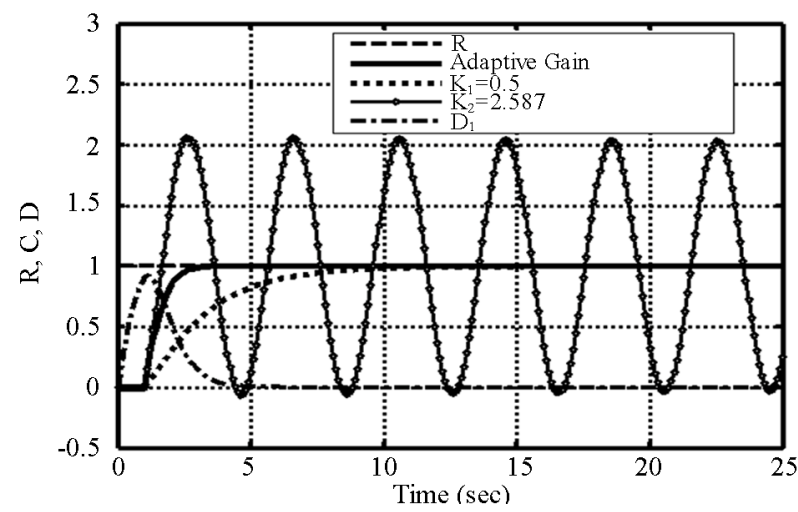

Figure 7. Step responses for constant gains $(K=0.5 \& 2.587)$ and adaptive gain with $D_{1}$ of Example 1. the combination of over-damped and zero-damped systems with $D_{1}$. Zero-damped system is used for fast responses and over-damped system is used for good performance. Naturally, it is input command $(R)$ independent also.

Simulation results of the proposed method and four other methods are presented for comparisons. They are Ziegler-Nichols method [18,19] for finding PI and PID compensators, Tan et al. [20,21] for finding PID compensator and Majhi [17] for finding PI compensator. Parameters of five found compensators are given below:

1) Proposed Method:

$K_{p}=1.1953 ; K_{i}=0.5942 ; K_{d}=0.7338$;

$K_{1}=0.5000 ; K_{2}=2.587 ; K_{n}=1.1385 ; T_{n}=0.6366$;

2) $Z N(P I): K_{p}=1.240$ and $K_{i}=0.251$.

3) $Z N(P I D)$ :

$K_{p}=1.6367, K_{i}=0.4187$ and $K_{d}=0.5972$.

4) Tan's (PID):

$K_{p}=0.620, K_{i}=0.5636$ and $K_{d}=0.1705$.

5) Majhi's (PI): $K_{p}=0.864$ and $K_{i}=0.3653$.

Time responses are shown in Figure 8. Gain/phase margins, phase/gain crossover frequencies, Integral of the Square Error (ISE), and Integral of the Absolute Error (IAE) are given in Table 1. From Table 1 and Figure 8, one can see that the proposed method gives faster response, better performance, and better robustness than those of other methods presented. Note that the proposed mrthod can provide a simple way to improved the system that has been controlled.

Example 2: Consider an electro-hydraulic velocity/position servo control system [22] shown in Figure 9. The relation between the servo spool position $X_{v}$ and the input voltage $\mathrm{u}$ is in the form of

$$
\frac{X_{v}}{u}=G_{v}(s)=\frac{K_{v}}{s^{2} / \omega_{v}^{2}+2 \xi_{v} s / \omega_{v}+1}
$$

where $K_{v}$ is the valve gain, $\xi_{v}$ is the damping ratio of the servo valve and $\omega_{v}$ is the natural frequency of the

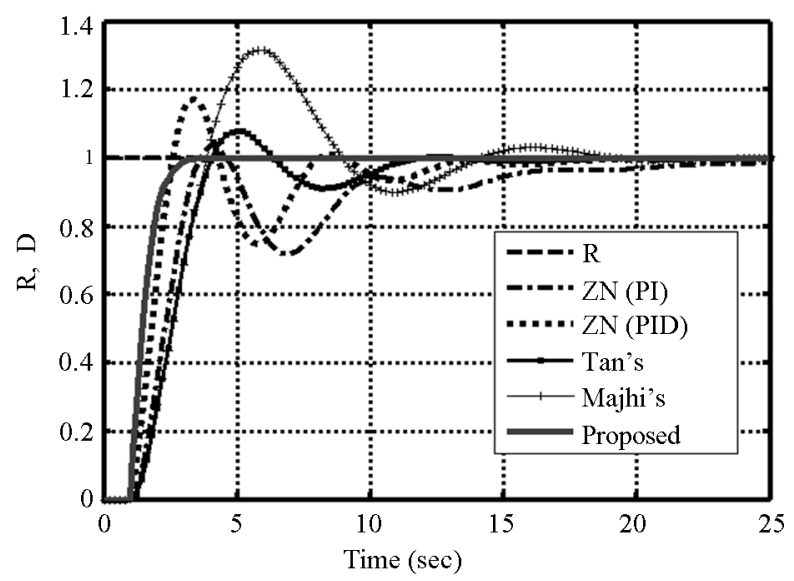

Figure 8. Comparisons with other methods for Example 1. 
Table 1. The gain/phase margins, phase/gain crossover frequencies, ISE and IAE of Example 1 using different methods.

\begin{tabular}{|c|c|c|c|c|c|c|}
\hline Method & $G M$ & $\omega_{C R P}(\mathrm{rad} / \mathrm{s})$ & $P M(\operatorname{deg})$ & $\omega_{C R G}(\mathrm{rad} / \mathrm{s})$ & ISE & $I A E$ \\
\hline Proposed & 3.941 & 1.653 & 78.45 & 0.322 & 1.359 & 1.687 \\
\hline ZN (PID) & 1.830 & 1.459 & 56.25 & 0.792 & 1.770 & 2.876 \\
\hline Tan’s (PID) & 2.418 & 0.929 & 38.30 & 0.488 & 2.247 & 3.073 \\
\hline Majhi's (PI) & 2.381 & 1.099 & 65.58 & 0.441 & 2.465 & 4.066 \\
\hline
\end{tabular}

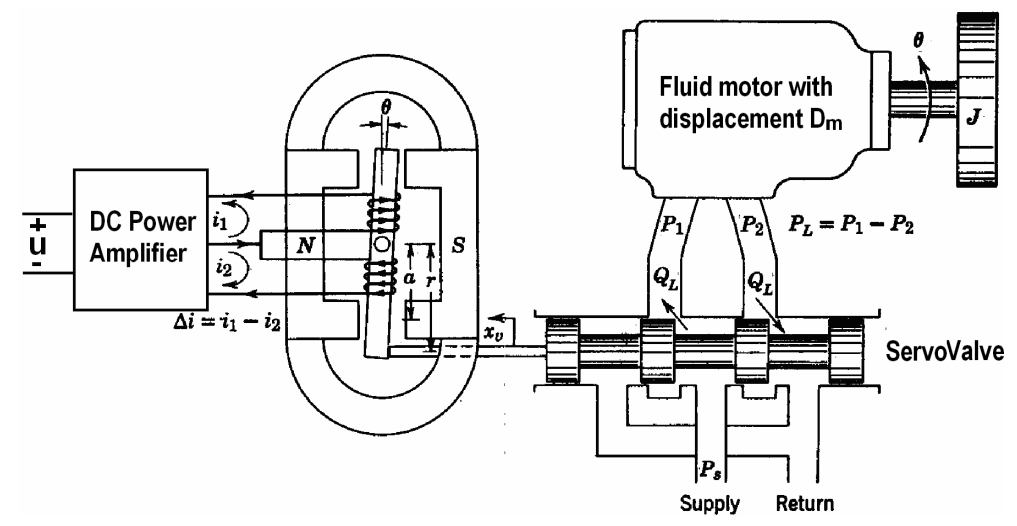

Figure 9. Block diagram of the electro-hydraulic system.

servo valve. In general, Equation (12) can be approximated by $X_{v}=K_{v} u$ for large $\omega_{v}$. The relation between the valve displacement $X_{V}$ and the load flow rate $Q_{L}$ is governed by the well-known orifice law [22]

$$
Q_{L}=X_{V} K_{J} \sqrt{P_{S}-\operatorname{sign}\left(X_{V}\right) P_{L}}=X_{V} K_{s}
$$

where $K_{j}$ is a constant for specific hydraulic motor; $P_{S}$ is the supply pressure; $P_{L}$ is the load pressure and; $K_{s}$ is the valve flow gain which varies at different operating points. The following continuity property of the servo valve and motor chamber yields

$$
Q_{L}=D_{m} \omega+C_{t p} P_{L}+\left(V_{t}-4 \beta_{o}\right) \dot{P}_{L} ;
$$

where $D_{m}$ is the volumetric displacement; $C_{t p}$ is the total leakage coefficient; $V_{t}$ is the total volume of the oil; $\beta_{o}$ is the bulk modulus of the oil; and $\omega$ is the velocity of the motor shaft. The torque balance equation for the motor is in the form of

$$
D_{m} P_{L}=J \dot{\omega}+B_{m} \dot{\omega}+T_{L} ;
$$

where $B_{m}$ is the viscous damping coefficient and $T_{L}$ is the external load disturbance which is assumed to be dependent upon the velocity of the shaft. The mathematical model of the considered system is shown in Figure 10. System parameters are given below:

$$
\begin{aligned}
& K_{s}=2.3 \times 10^{-7} \sqrt{P_{S}-\operatorname{sign}\left(X_{V}\right) P_{L}} \mathrm{~m}^{2} / \mathrm{s} ; \\
& P_{S}=1.4 \times 10^{7} \mathrm{~N}_{\mathrm{t}} / \mathrm{m}^{2} ; K_{v}=0.5 \mathrm{~m} / \mathrm{v} ;
\end{aligned}
$$

$$
\begin{aligned}
& \beta_{o}=3.5 \times 10^{7} \mathrm{~N}_{\mathrm{t}} / \mathrm{m}^{2} ; V_{t}=3.3 \times 10^{-5} \mathrm{~m}^{2} / \mathrm{rad} ; \\
& C_{t p}=2.3 \times 10^{-11} \mathrm{~m}^{2} / \mathrm{s} / \mathrm{N}_{\mathrm{t}} ; D_{m}=1.6 \times 10^{-5} \mathrm{~m}^{3} / \mathrm{rad} ; \\
& J=5.8 \times 10^{-3} \mathrm{Kg} \cdot \mathrm{m} \cdot \mathrm{s}^{2} ; B_{m}=0.864 \mathrm{Kg} \cdot \mathrm{m} \cdot \mathrm{s} / \mathrm{rad} ; \\
& \xi_{v}=0.4 ; \quad \omega_{v}=628 \mathrm{rad} / \mathrm{s} .
\end{aligned}
$$

The control configuration for velocity and position servo control of the considered system is shown in Figure 11, in which inner loop and outer loop adaptive nonlinear controllers are included.

Design results of the velocity control loop are discussed below:

\section{1) Inner loop PI controller}

The PI controller is first found by the optimization toolbox of MATLAB for minimized the integration of absolute errors (IAE), integration of square errors (ISE) and zero peak overshoot. Parameters of the PI controller are $K_{p}=1.127 \times 10^{-3}$ and $K_{i}=3.9632$. Time responses of the controlled system using the found PI controller are shown in Figure 12.

2) Parameters of inner loop adaptive nonlinear controller

Low gain $\left(K_{1}=1\right)$ and high gain $\left(K_{2}=9.223\right)$ are selected. The low gain case is the optimized result and the high gain case is the controlled system in the sustaining condition $\left(\omega_{n}=312.71 \mathrm{rad} / \mathrm{s}\right)$. The

$\omega_{n}=312.71 \mathrm{rad} / \mathrm{s}$ gives $T_{n}=0.003182 . K_{n}=2.2889$ is found by Equations (8) and (9) using $M_{p s}=1.001$. 


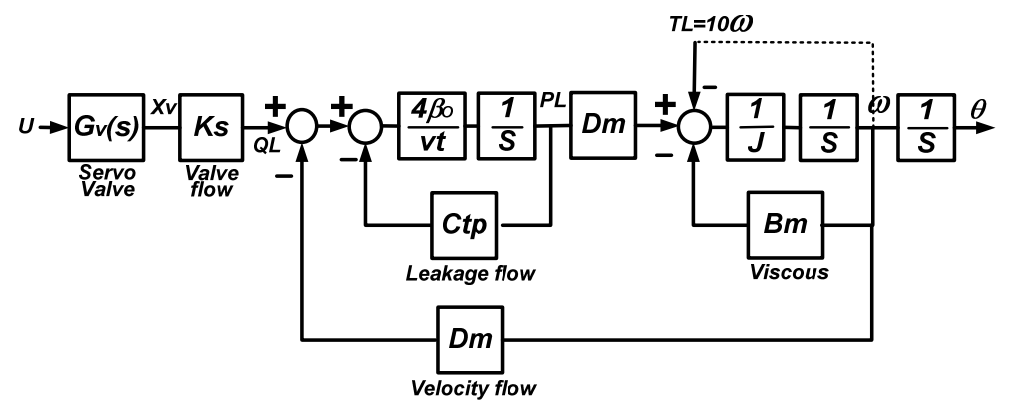

Figure 10. Mathematic model of the electro-hydraulic system.

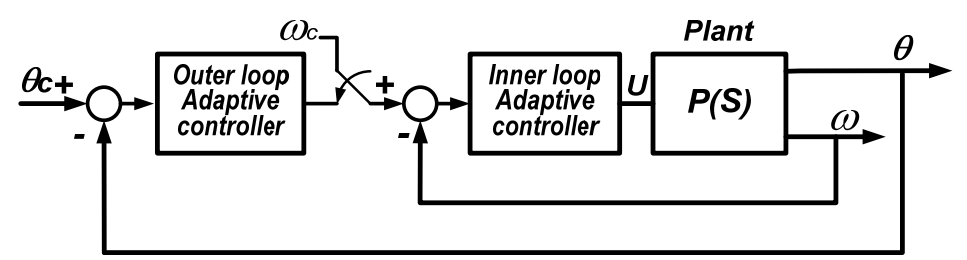

Figure 11. Control configuration of velocity and position servo control system.

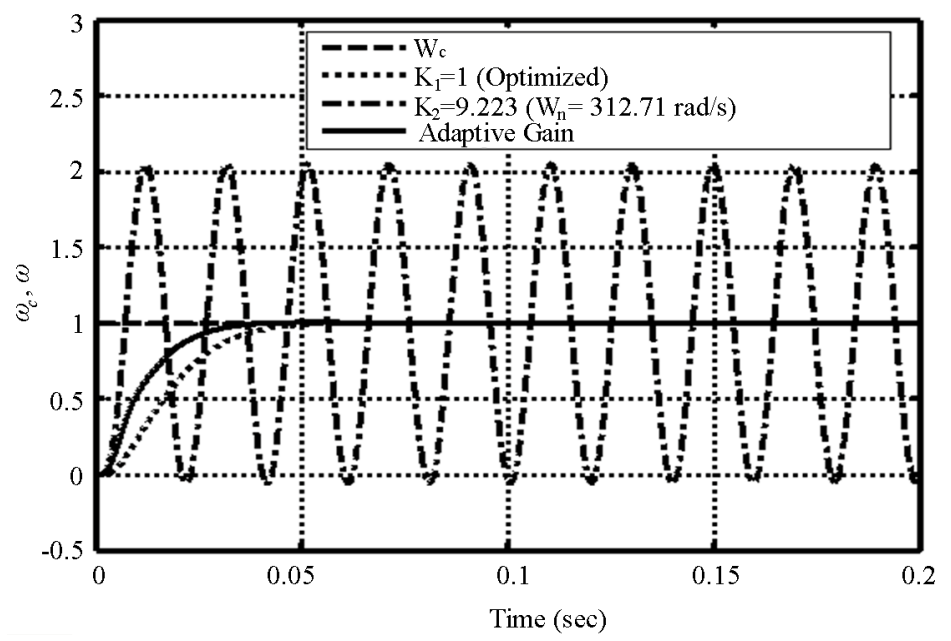

Figure 12. Time responses of velocity control system for low gain $\left(K_{1}=1\right)$ and high gain $\left(K_{2}=9.223\right)$ and adaptive gain.

Time responses for low gain, high gain and adaptive gain are shown in Figure 12. Rise times of the optimization method and the proposed method are $0.0202 \mathrm{sec}$ and $0.0124 \mathrm{sec}$; respectively. It shows the proposed method can give faster response than that of controlled by the optimized method. The Gain gain/phase margins, phase/gain crossover frequencies, and rise times are given also in Table 2. It gives controlled system using two methods have same robustness while Figure 12 shows the proposed method gives faster response.

Design results of the position control loop are discussed below:

\section{1) Outer loop PI controller}

The PI controller are first found by the optimizations toolbox of MATLAB for minimized the integration of absolute errors (IAE), integration of square errors(ISE) and zero peak overshoot. Parameters of the PI controller are $K_{p}=18.506$ and $K_{i}=0.3666$. Time responses of the controlled system using the found PI controller are shown in Figure 13.

2) Parameters of outer adaptive nonlinear controller

Low gain $\left(K_{1}=1\right)$ and high gain $\left(K_{2}=7.877\right)$ are selected. The low gain case is the optimized result and the high gain case is the controlled system in the sustaining condition $\left(\omega_{n}=91.95 \mathrm{rad} / \mathrm{s}\right)$. The

$\omega_{n}=91.95 \mathrm{rad} / \mathrm{s}$ gives $T_{n}=0.0010875 . K_{n}=13.5$ is found by Equations (8) and (9) using $M_{p s}=1.001$. Time responses for low gain, high gain, and adaptive gain are shown in Figure 13. Rise times of the optimization method and the proposed method are $0.0513 \mathrm{sec}$ and $0.0334 \mathrm{sec}$; respectively. It shows the proposed method can give faster response than that of controlled by the optimized method. The Gain gain/phase margins, pha- 
Table 2. Gain/phase margins, phase/gain crossover frequencies and rise times.

\begin{tabular}{cccccc}
\hline Method & GM & $\omega_{c p}(\mathrm{~Hz})$ & $\begin{array}{c}\text { PM } \\
\text { (deg.) }\end{array}$ & $\omega_{c g}(\mathrm{~Hz})$ & $\begin{array}{c}\text { Rise Time } \\
\text { (sec) }\end{array}$ \\
\hline Optimization & $\mathbf{9 . 0 5}$ & $\mathbf{5 0 . 0 3}$ & 69.35 & 8.13 & $\mathbf{0 . 0 2 0 2}$ \\
Adaptive Gain & $\mathbf{9 . 1 9}$ & 49.73 & 69.35 & 8.13 & $\mathbf{0 . 0 1 2 4}$ \\
\hline
\end{tabular}

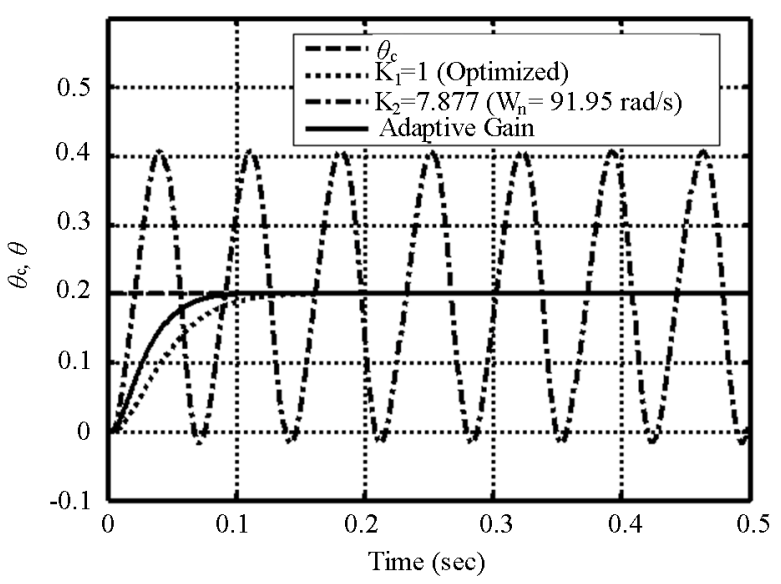

Figure 13. Time responses of position control system for $K_{1}=1, \quad K_{2}=7.877$ and adaptive gain.

Table 3. Gain/phase margins, phase/gain crossover frequencies and rise times.

\begin{tabular}{cccccc}
\hline Method & GM & $\omega_{c p}(\mathrm{~Hz})$ & $\begin{array}{c}\text { PM } \\
\text { (deg.) }\end{array}$ & $\omega_{c g}(\mathrm{~Hz})$ & Rise Time (sec) \\
\hline Optimization & 8.35 & 47.19 & 52.14 & 8.91 & 0.0513 \\
Adaptive Gain & 8.39 & 47.22 & 51.09 & 8.71 & 0.0334 \\
\hline
\end{tabular}

se/gain crossover frequencies and rise times are given also in Table 3. It gives controlled system using two methods have same robustness while Figure 13 shows the proposed method gives faster response.

\section{Conclusions}

The proposed adaptive piecewise linear controller has been shown that provided controlled systems are reference input independent and both good performance and fast response were obtained simultaneously. Three segments piecewise linear controller provided a switching algorithm for low gain and high systems; i.e., low gain for performance and high gain for response time. The switching points were dependent on the command tracking errors. There are zero-damped ones used in Example 1 and 2 to get fast responses in large tracking error phases.

Two servo control system examples were designed and comparisons were made with famous on-line computing and control methods and optimization method. They have illustrated better performance and fast response of the proposed method than those of other mentioned methods.

\section{REFERENCES}

[1] B. C. Kuo and F. Golnaraghi, "Automatic Control Systems," 8th Edition, John Wiley \& Sons, Inc., Hoboken, 2003.

[2] R. C. Dorf and R. H. Bisop, "Modern Control Systems," 7th Edition, Pearson Education Singapore Pte, Ltd., Singapore, 2008.

[3] V. I. Utkin, "Variable Structure Systems with Sliding Modes," IEEE Transactions on Automatic Control, Vol. 22, No. 2, 1977, pp. 212-222.

http://dx.doi.org/10.1109/TAC.1977.1101446

[4] G. Bartolini, E. Punta and T. Zolezzi, "Simplex Methods for Nonlinear Uncertain Sliding-Mode Control," IEEE Transactions on Automatic Control, Vol. 49, No. 6, 2004, pp. 922-933. http://dx.doi.org/10.1109/TAC.2004.829617

[5] J. Y. Hung, W. Gao and J. C. Hung, "Variable Structure Control: A Survey," IEEE Transactions on Industry Electron, Vol. 40, No. 1, 1993, pp. 2-22. http://dx.doi.org/10.1109/41.184817

[6] G. Bartolini, A. Ferrara, E. Usai and V. I. Utkin, "On Multi-Input Chattering-Free Second Order Sliding Mode Control," IEEE Transactions on Automatic Control, Vol. 45, No. 9, 2000, pp. 1711-1717.

http://dx.doi.org/10.1109/9.880629

[7] S. R. Vadali, "Variable-Structure Control of Spacecraft Large-Angle Maneuvers," Journal of Guidance, Control, and Dynamics, Vol. 9, No. 2, 1986, pp. 235-239. http://dx.doi.org/10.2514/3.20095

[8] M. Corno, M. Tanelli, S. M. Savaresi and L. Fabbri, "Design and Validation of a Gain-Scheduled Controller for the Electronic Throttle Body in Ride-by-Wire Racing Motorcycles," IEEE Transactions on Control Systems Technology, Vol. 19, No. 1, 2011, pp. 18-30. http://dx.doi.org/10.1109/TCST.2010.2066565

[9] R. A. Nichols, R. T. Reichert and W. J. Rugh, "Gain Scheduling for H-Infinity Controllers: A Flight Control Example," IEEE Transactions on Control Systems Technology, Vol. 1, No. 2, 1993, pp. 69-79. http://dx.doi.org/10.1109/87.238400

[10] T. A. Johansen, I. Petersen, J. Kalkkuhl and J. Ludemann, "Gain-Scheduled Wheel Slip Control in Automotive Brake Systems," IEEE Transactions on Control Systems Technology, Vol. 11, No. 6, 2003, pp. 799-811. http://dx.doi.org/10.1109/TCST.2003.815607

[11] J. H. Taylor and K. Strobel, "Nonlinear Compensator Synthesis via Sinusoidal-Input Describing Functions," Proceedings of American Control Conference, Boston, 1985, pp. 1242-1247.

[12] R. D. Colgern and A. Jonckheere, "H Control of a Class of Nonlinear Systems Using Describing Functions and Simplicial Algorithms," IEEE Transactions on Automatic Control, Vol. 42, No. 5, 1997, pp. 707-712. http://dx.doi.org/10.1109/9.580883

[13] A. Nassirharand and H. Karimi, "Controller Synthesis 
Methodology for Multivariable Nonlinear Systems with Application to Aerospace," ASME Journal of Dynamic and System Measurement Control, Vol. 126, No. 3, 2004, pp. 595-604. http://dx.doi.org/10.1115/1.1789975

[14] A. Nassirharand and H. Karimi, "Nonlinear Controller Synthesis Based on Inverse Describing Function Technique in the MATLAB Environment," Advances in Engineering Software, Vol. 37, No. 6, 2006, pp. 370-374. http://dx.doi.org/10.1016/j.advengsoft.2005.09.009

[15] W. K. Ho, T. H. Lee, H. P. Han and Y. Hong, "Self-Tuning IMC-PID Controller with Gain and Phase Margins Assignment," IEEE Transactions on Control System Technology, Vol. 9, No. 3, 2001, pp. 535-541.

[16] T. S. Tsay, "On-Line Computing of PI/Lead Compensators for Industry Processes with Gain and Phase Specifications," Computers and Chemical Engineering, Vol. 33, No. 9, 2009, pp. 1468-1474.

http://dx.doi.org/10.1016/j.compchemeng.2009.05.001

[17] S. Majhi, "On-Line PI Control of Stable Process," Journal of Process Control, Vol. 15, No. 8, 2005, pp. 859-867. http://dx.doi.org/10.1016/j.jprocont.2005.04.006

[18] J. G. Ziegler and N. B. Nichols, "Optimum Setting for Automatic Controller," Transactions of ASME, Vol. 65, 1942, pp. 759-768.

[19] K. J. Áström and T. Hägglund, "Revisting the ZieglerNichols Step Responses Method for PID Control," Journal of Process Control, Vol. 14, No. 6, 2004, pp. 635-650. http://dx.doi.org/10.1016/j.jprocont.2004.01.002

[20] K. K. Tan, T. H Lee and X. Jiang, "Robust On-line Relay Automatic Tuning of PID Control System," ISA Transactions, Vol. 39, 2000, pp. 219-232.

[21] K. K. Tan, T. H. Lee and X. Jiang, "On-Line Relay Identification, Assessment and Tuning of PID Controller," Journal of Process Control, Vol. 11, No. 5, 2001, pp. 483486. http://dx.doi.org/10.1016/S0959-1524(00)00012-3

[22] H. E. Merritt, "Hydraulic Control System," John Wiley, New York, 1967. 